\title{
NOTES
}

\section{The Limited-Area Fine-Mesh Model and Quasi-Geostrophic Theory: A Disturbing Case Study}

\author{
STANLEY L. BARNES \\ Weather Research Program, NOAA, Environmental Research Laboratories, Boulder, CO 80303
}

31 July 1985 and 28 January 1986

\section{Introduction}

The purpose of this note is to demonstrate the value of quasi-geostrophic (QG) diagnostics for evaluating numerical model performance with regard to synopticscale dynamics. In an application of QG theory to a weakly forced convective storm episode, Barnes (1985; henceforth B85) obtained results that raise questions concerning the Limited-Area Fine-Mesh Model's (LFM) 12-h forecast performance. Here, attention is drawn to the problem encountered in the case of 2526 June 1982, and since the case concerns flow over the mountainous western United States, we investigate the possibility that orographic forcing might have contributed to the discrepancies found.

Vertical motions associated with traveling, baroclinic systems seen on weather maps as troughs and ridges, or lows and highs, can be diagnosed from QG theory. The QG vertical motions are forced by vertical differential vorticity advection and an often nearly equal but opposite contribution from thermal advection (more precisely, the Laplacian of thermal advection). Trenberth (1978) points out that by making an arguably small approximation these two forcing effects can be combined mathematically and estimated from a weather map containing thickness and vorticity contours. Quasi-geostrophic vertical motion patterns can be visualized by advecting vorticity with a representative thermal wind. Thus, layers characterized by positive (negative) vorticity advection by the thermal wind are being forced to rise (descend). Hoskins et al. (1978) use the more general QG omega equation, which includes the term ignored by Trenberth, namely, the advective changes of temperature gradient owing to deformations in the geostrophic wind field. Presumably, the contribution from this effect is small except near the earth's surface and in the upper troposphere.

Not all of the contributions to the atmosphere's vertical motion can be explained by QG theory. Convective storms, the diurnal heating and cooling cycle, mountainous terrain, frictional effects on air motion near the earth's surface, and other nongeostrophic effects all influence vertical motions. None of these effects are accounted for by QG theory.
Vertical motions predicted by the LFM include both explicit and parameterized physics that attempt to describe the effects of these nongeostrophic influences (Gerrity, 1977). Therefore, when nongeostrophic influences are large relative to geostrophic contributions to vertical motions, one should expect the LFM vertical motions to deviate somewhat from those which are diagnosed on the basis of QG theory alone. On the other hand, when the actual winds are largely geostrophic throughout the troposphere. Hopefully, it is not being naive to expect the LFM's prediction of vertical motions to deviate only modestly from QG theory.

In B85, the LFM's vertical motion predictions and model output statistics (MOS) guidance have been compared to QG diagnostic information based on $o b$ served data. It was noted that the LFM run for 1200 GMT 25 June 1982 in its 12-h prediction of $700 \mathrm{mb}$ vertical motion did not indicate a region of relatively strong upward motion that was suggested by the predicted thermal wind (1000-500 mb thickness) advection of $500 \mathrm{mb}$ vorticity. Furthermore, in the same prediction the LFM placed a center of strong upward motion where little geostrophic forcing could be found. Curiosity about the LFM's gross departure from QG theory led to this study. Here, the approach taken contrasts LFM predictions of vertical motions with $Q G$ diagnostics computed from the LFM's predicted height fields at 850,700 and $500 \mathrm{mb}$. This comparison raises a question as to what drives the LFM's computation of vertical motions in relatively weak baroclinic cases. The study does not attempt to provide an answer, since that would require information concerning the LFM that is not in the published literature as well as access to the complete model output for this case. Rather, the study suggests that alternative products based on QG theory might be useful to field forecasters for evaluating quality of numerical prediction guidance.

\section{Review of $25-26$ June $\mathbf{1 9 8 2}$}

The weather events on this day are discussed in more detail in B85. By 0000 GMT 26 June 1982, thunderstorms had developed along the Rocky Mountains from 
New Mexico to Montana and were moving onto the high plains (Fig. 1). Many of the storms in southern Wyoming and northern Colorado were severe, and soon after $0000 \mathrm{GMT}$ a mesoscale convective complex (MCC) developed in eastern Colorado. These events took place ahead of a short-wave trough at $500 \mathrm{mb}$ (Fig. 2) and, as shown in B85, were associated with geostrophically forced circulations as revealed by the field of $Q$-vectors (Hoskins et al., 1978; Hoskins and Pedder, 1980).

In this case, the LFM vertical motion guidance (700 $\mathrm{mb}$ omega) received in National Weather Service (NWS) field forecast offices did not predict (from initial conditions $12 \mathrm{~h}$ earlier) the synoptic-scale upward motions that apparently contributed to the organization of the storms into an MCC. But, as we shall next discover, unavailable information from the LFM predictions based on that morning's data might have been useful to field forecasters.

\section{The LFM predictions}

Computer printouts of gridded data from the LFM run for 1200 GMT 25 June 1982 were obtained from the NWS Techniques Development Laboratory. Parameter values for an 18 by 14 portion of the LFM mesh were entered manually into a microcomputer, where they were contoured and printed to produce most of the figures in this note. Figure 3 illustrates the $12 \mathrm{~h}$ predicted omega fields at both 500 and $700 \mathrm{mb}$, valid at 0000 GMT 26 June 1982.

Upward motion predicted at $500 \mathrm{mb}$ (Fig. 3a) over southeastern Wyoming and north-central Colorado shows good correlation with the area in which thunderstorms began organizing into an MCC (Fig. 1). However, the $500 \mathrm{mb}$ omegas were not available to field forecasters who were faced with the problem of trying to understand the $700 \mathrm{mb}$ omega field (Fig. 3b). Over Utah at $700 \mathrm{mb}$, upward motion is predicted to the west of the predicted positions of the upper trough and the $850 \mathrm{mb}$ low (Fig. 4). Also over Utah, negative vorticity advection by the $1000-500 \mathrm{mb}$ thermal wind is predicted (Fig. 5), inferring geostrophically forced descent. Furthermore, it can be seen from Fig. 5 that the predicted upward motion maximum over northern Idaho (Fig. 3) has little support from QG theory. There is very little thermal wind to advect vorticity, and what there is will contribute to geostrophically forced descent.

Except for the northern Utah center of $700 \mathrm{mb}$ upward motion and the lack of a center in northern Colorado, Fig. 3 does indicate general correlation between the major centers of vertical motions at 500 and 700 mb. Since both of these levels are between the LFM's first and second levels above the boundary layer (roughly, 710 and $490 \mathrm{mb}$ ), this consistency may be due in part to the interpolation required to transfer results computed in the LFM's sigma coordinate sys- tem to the pressure coordinate system used to display National Meteorological Center (NMC) products for field use. Nonetheless, there are features at $700 \mathrm{mb}$ that probably cannot be explained by coordinate transformation, which prompted the following cursory examination of the low-level vertical motions induced by predicted flow over the terrain.

\section{Orographic forcing}

Gridded values of the terrain elevation used in the LFM were entered into the microcomputer and contoured, producing Fig. 6 . Using this topography and the geostrophic winds computed separately from 850 and $700 \mathrm{mb}$ predicted heights (Fig. 4), we estimated orographically induced vertical motions simply by computing the predicted geostrophic wind's component along the terrain gradient (Fig. 7). It is not presumed that the magnitudes of the orographic vertical motion centers have been accurately determined by this approach, only that the sense of orographic com-

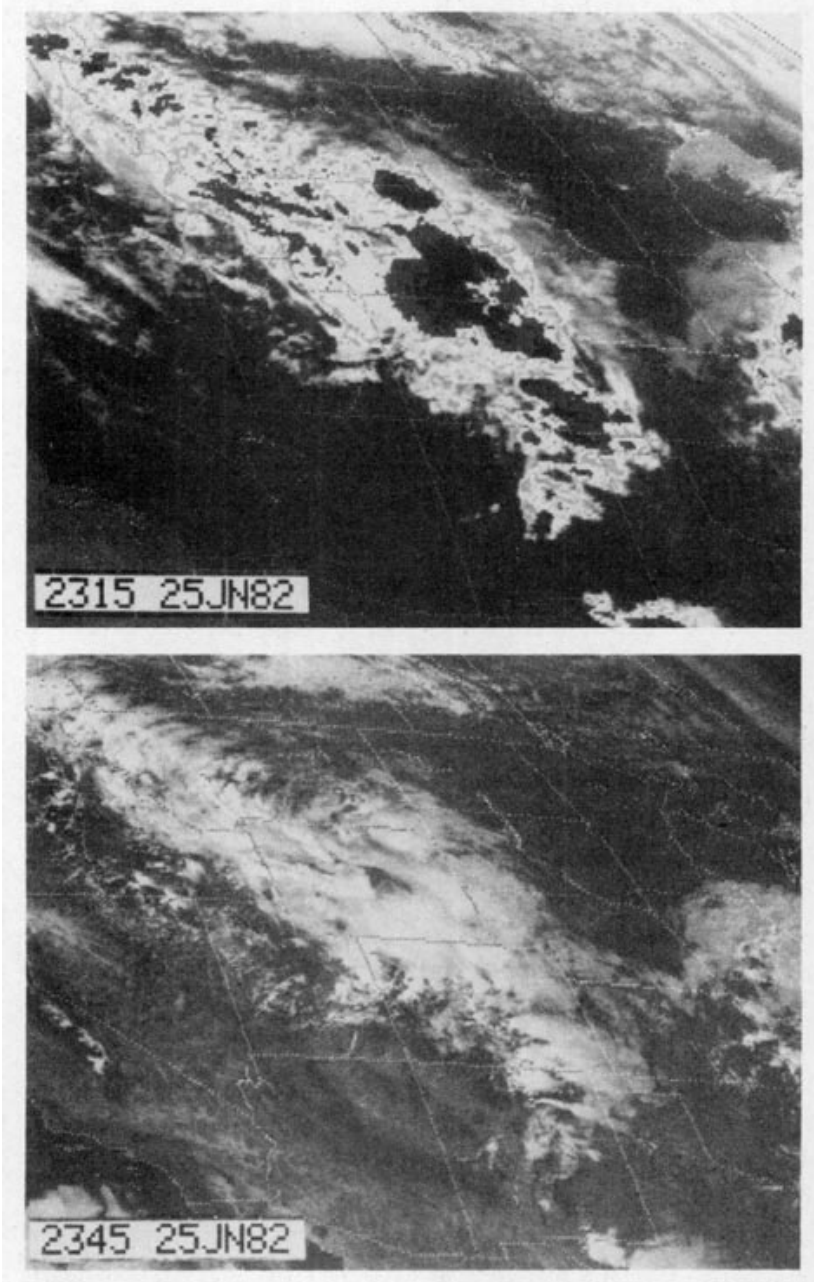

FIG. 1. Satellite infrared and visible images of convective activity near time of LFM vertical motion predictions shown in Fig. 3. 


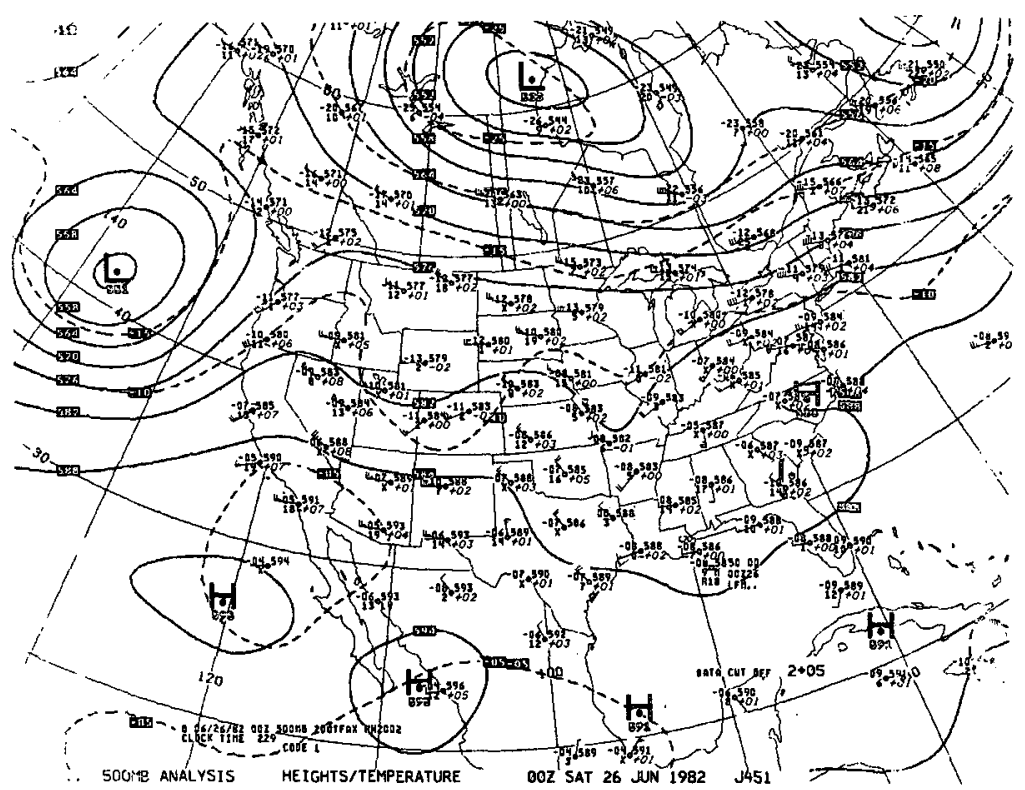

FIG. 2. National Meteorological Center's $500 \mathrm{mb}$ map for 0000 GMT 26 June 1982. Height contours are in dam at 60 -m intervals; isotherms (dashed) are depicted at $5^{\circ} \mathrm{C}$ intervals. Convective storms shown in Fig. 1 are associated with weak trough approaching Wyoming and Colorado.

ponent has been analyzed as it probably should appear in the LFM.

It is apparent that the narrow strip of LFM-predicted upward motion from northwestern New Mexico through northern Utah (Fig. 3b) may be in part due to the orographic component in that area (Fig. $7 ;-4$ $\mathrm{mb} \mathrm{h}^{-1}$ ). But at $500 \mathrm{mb}$ over northern Colorado, the predicted upward motion center (Fig. 3a) is not supported by orographically induced motions from below, as there is descent indicated at both 850 and $700 \mathrm{mb}$ (Fig. 7). Here, the applicability of this simple orographic analysis should be questioned because of the meteo- rology of the situation. The Front Range area of Colorado was overlain by a relatively deep, polar air mass with a $15 \mathrm{~K}$ increase in potential temperature from the surface to its top near $690 \mathrm{mb}$ (see B85). Furthermore, cool air within the polar air mass was being replenished by upslope flow from the southeast. At Denver, $9 \mathrm{~K}$ of daytime heating was insufficient to remove the frontal inversion. Under this circumstance, air moving from the west and forced to ascend over the mountains would not likely return to the surface in their lee. Has the LFM accounted for this circumstance by indicating weak $700 \mathrm{mb}$ upward motion instead of descent along
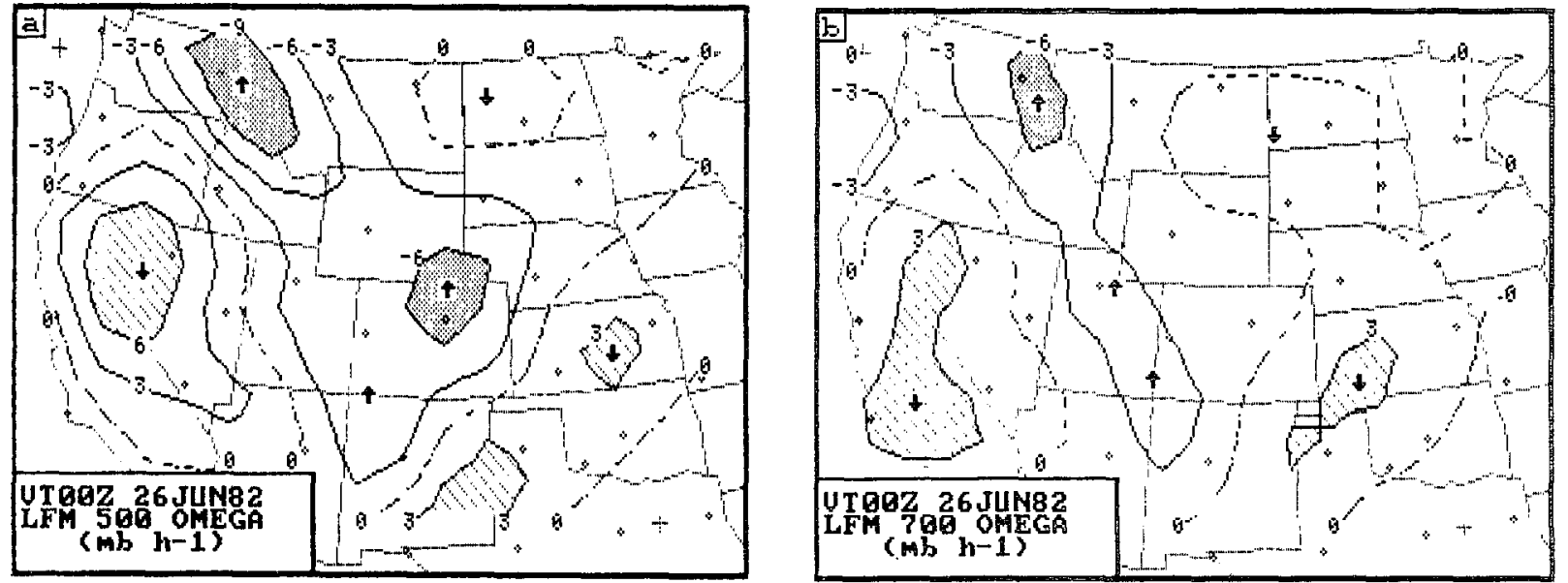

FIG. 3. Microcomputer-contoured representation of LFM gridpoint data depicting $12 \mathrm{~h}$ forecast of omega (vertical motion; mb $\mathrm{h}^{-1}$ ) at (a) $500 \mathrm{mb}$ and (b) $700 \mathrm{mb}$, valid at 0000 GMT 26 June 1982. 

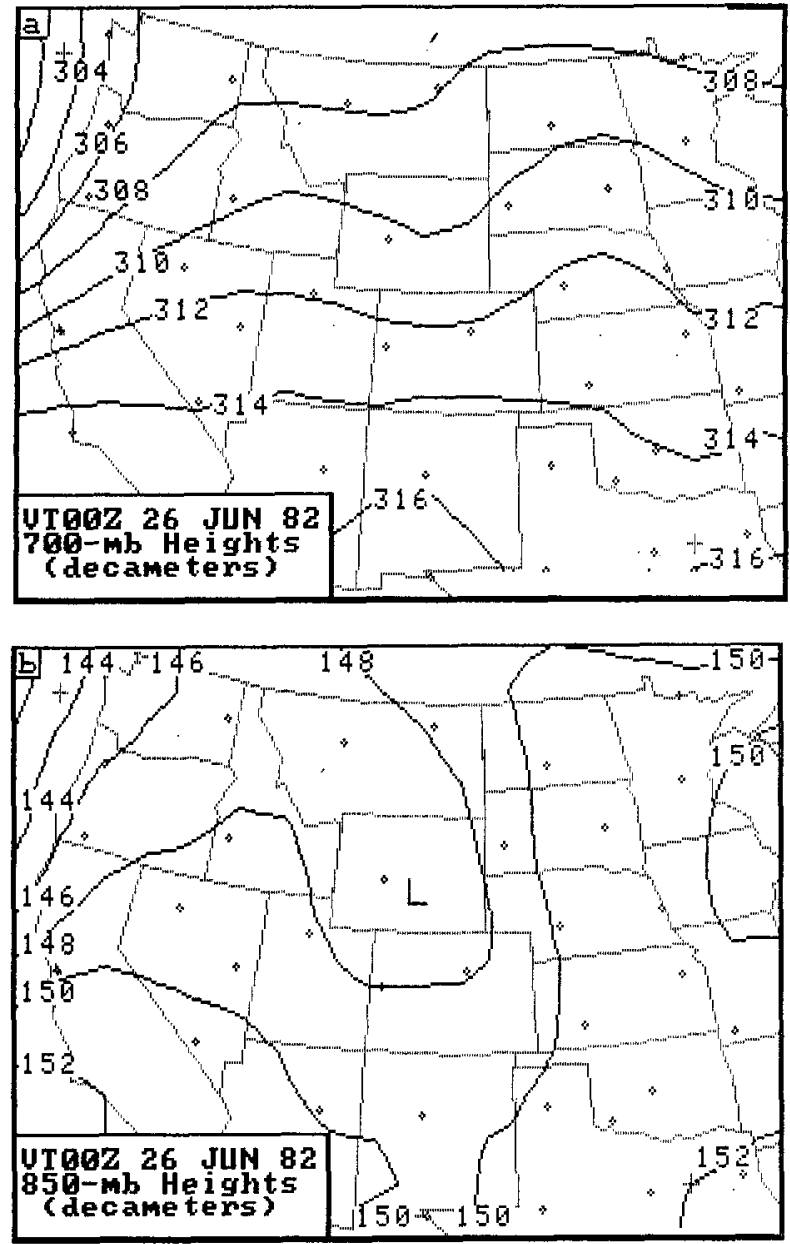

FIG. 4. Microcomputer representation of LFM $12 \mathrm{~h}$ prediction of 700 and $850 \mathrm{mb}$ heights, valid at 0000 GMT 26 June 1982. Contours are labeled in decameters.

the Front Range? Perhaps. The LFM's predicted boundary-layer vertical motions (not shown) indicated essentially no forcing in the Denver area. Elsewhere, the predicted boundary-layer motion centers have very little correlation with the $700 \mathrm{mb}$ vertical motions.

As for the orographic components elsewhere, in northern Idaho it is apparent that the predicted strong upward motion center (Fig. 3) must be due to something other than terrain forcing. Neither does the LFM's boundary layer prediction indicate any forcing in Idaho, and one terrain-induced center, in northern California, is not reflected at all in the LFM's $700 \mathrm{mb}$ vertical motion prediction-again for reasons that are obscure. This analysis of terrain forcing has done little to clarify the reasons behind the LFM's performance in this case.

\section{A forecaster's dilemma}

The point of the preceding discussion is that even if a forecaster had all this information and time to ponder its meaning, he/she probably would be left with a great deal of uncertainty and confusion about the guidance provided by the LFM's $700 \mathrm{mb}$ vertical motion prediction. Based upon this prediction, a forecaster might presume that the short-wave trough passing through Wyoming and northern Colorado was to be dynamically weak. As for the vertical motions predicted elsewhere, orographically forced vertical motions cannot explain many features in the LFM's vertical motion prediction. If the predicted motions are not attributable to terrain forcing or geostrophic forcing, then to what physical cause(s) do they owe their existence? As noted in the Introduction, this question cannot be answered from the information readily available to this researcher, much less to a forecaster within the time frame of his operational requirements. What then is a forecaster to do when faced with such numerical guidance? Probably, most will respond in one or a combination of the following ways: 1) accept the numerical guidance whether or not they believe it; 2) follow their own "rules of thumb"; 3 ) follow locally developed guidelines.

Of those forecasters who attempt to evaluate the situation according to the second of the above possibilities, many will estimate qualitatively the synoptic-scale dynamics using what they know of QG theory (e.g., positive vorticity advection, thermal advection). In this regard, the most readily available tool they have to work with is predicted $500 \mathrm{mb}$ vorticity and 1000-500 mb thickness (Fig. 5). Across Colorado and southern Wyoming there is positive vorticity advection by the thermal wind. Here, the vorticity gradient is especially strong, but the thickness gradient (thermal wind) is stronger over western South Dakota. What is the distribution of geostrophic forcing associated with such a pattern? The simple tools required to evaluate this

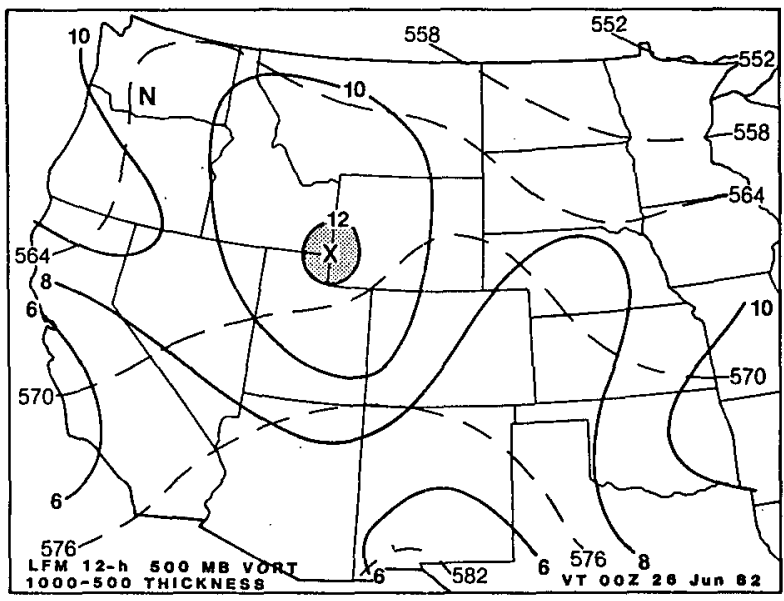

FIG. 5. LFM $12 \mathrm{~h}$ predicted $500 \mathrm{mb}$ absolute vorticity and thickness (dashed) for 1000-500 mb layer, valid at 0000 GMT 26 June 1982. Vorticity isopleths are in units of $10^{-5} \mathrm{~s}^{-1}$; thickness contours are in decameters. 


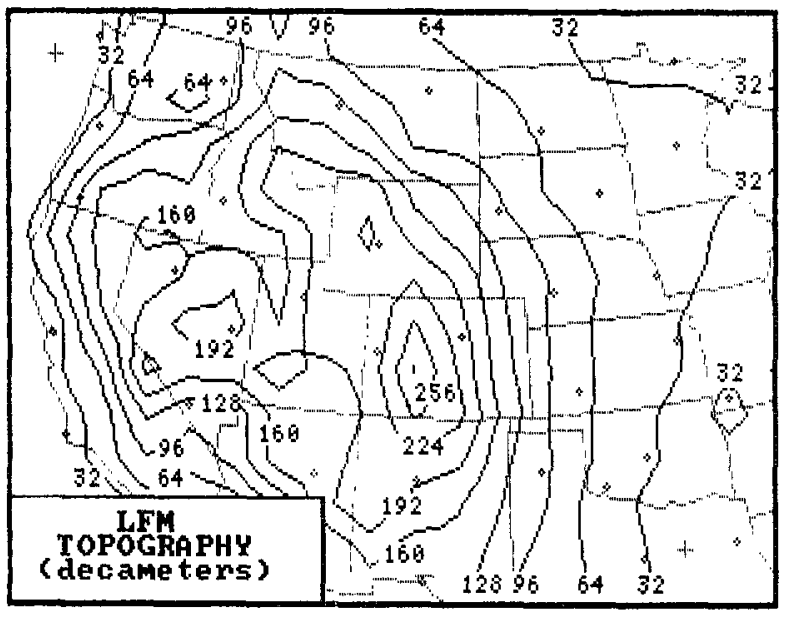

FIG. 6. LFM topography (in dam) mapped from grid point data. Mesh size is indicated by distance from cross near upper left corner to the corner, which is also a grid point.
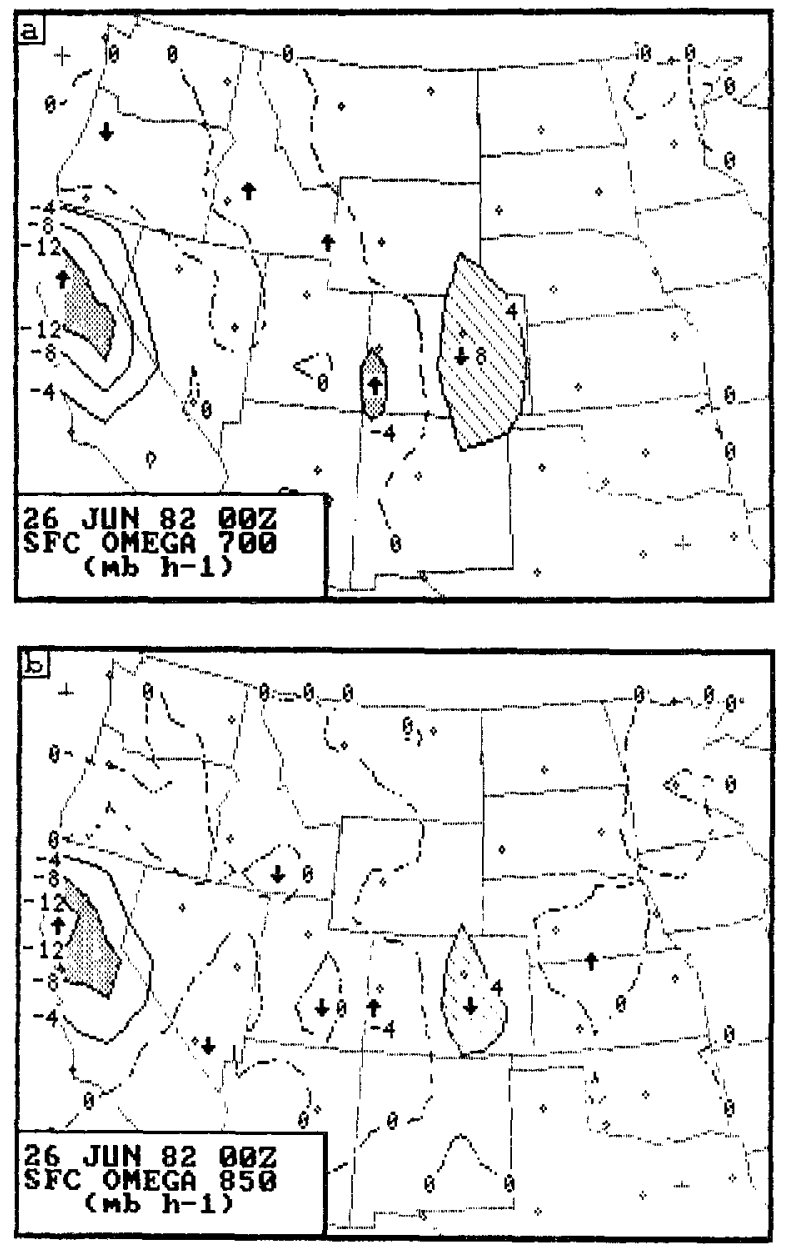

FIG. 7. Orographically forced vertical motions for 0000 GMT 26 June 1982 at 700 and $850 \mathrm{mb}$ computed as component of predicted geostrophic wind (Fig. 4) along terrain gradient (Fig. 6). forcing are available, but they are not in place operationally.

\section{Quasi-geostrophic diagnostics from predicted height fields}

Quasi-geostrophic diagnostics were computed from the LFM predicted height fields at 850,700 and 500 $\mathrm{mb}$ for 0000 GMT 26 June 1982. These three height fields were diagnosed in the same manner as were the gridded values interpolated from observations in B85. The resulting $700 \mathrm{mb}$ omega distribution (actually, divergence of the $Q$-vector field scaled to look like vertical velocity) is illustrated in Fig. 8.

The $700 \mathrm{mb}$ diagnosed omegas have many features that are similar to the LFM omegas (Fig. 3b). Air descending over California and over a zone from southeastern New Mexico to lowa is configured similarly in both figures. The magnitudes of diagnosed descent are different from the LFM values, but since the diagnosed values are not truly omegas, we are not at liberty to compare them in an absolute sense. However, we can compare the relative strengths of the diagnosed centers with the relative strengths of the same centers predicted by the LFM. The diagnosis indicates that the air masses in California and from New Mexico to Iowa are descending through $700 \mathrm{mb}$ at about the same rate (both $8 \mathrm{mb} \mathrm{h}^{-1}$ ), and, in a relative sense, the LFM agrees (both $3 \mathrm{mb} \mathrm{h}^{-1}$ ). In these two areas, it is obvious that the LFM vertical motions are driven mostly by geostrophic forcing.

Elsewhere, differences between LFM and QG omegas abound. At $700 \mathrm{mb}$, the $-6 \mathrm{mb} \mathrm{h}^{-1}$ LFM center over Idaho is not found in the diagnosed vertical motions (Figs. 3b and 8). Its physical source in the LFM is not known, but we have seen that it is not due to terrain forcing. Utah and western Wyoming are loca-

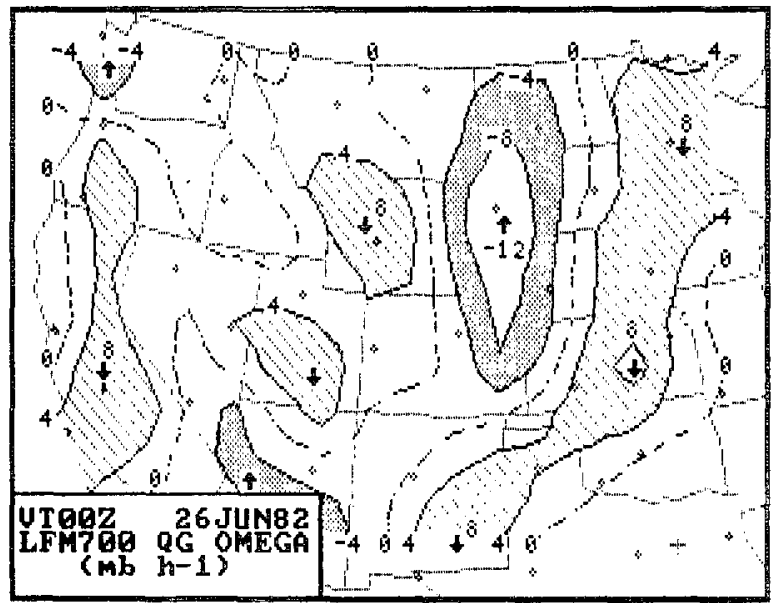

Fig. 8. Vertical motions diagnosed from $Q$-vector representation of geostrophic forcing at $700 \mathrm{mb}$. Isotachs are in relative, not absolute, units $\left(\mathrm{mb} \mathrm{h}^{-1}\right)$. Computations are based on LFM $12 \mathrm{~h}$ predicted height fields at 850,700 and $500 \mathrm{mb}$ for 0000 GMT 26 June 1982. 


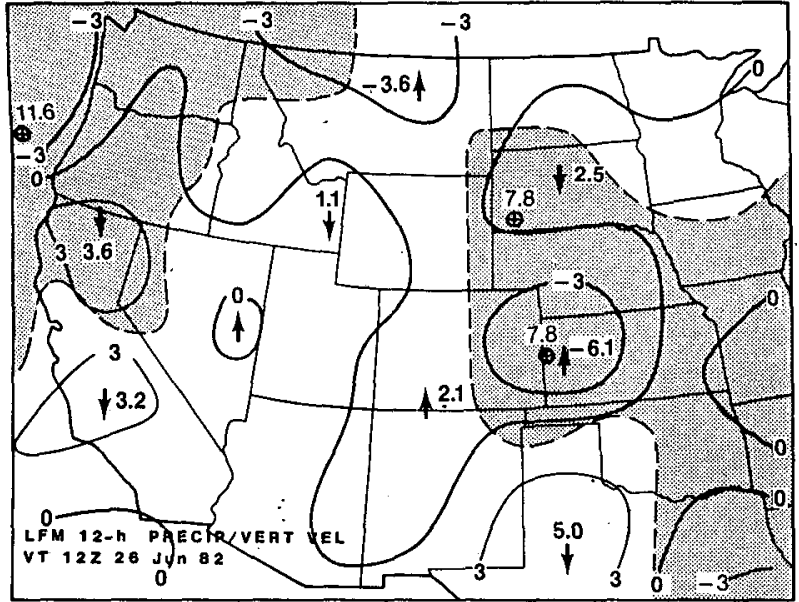

FIG. 9. LFM $12 \mathrm{~h}$ predicted precipitation (stippled areas;' maxima in $\mathrm{mm}$ are marked by $\oplus$ ) and $700 \mathrm{mb}$ vertical motion (bold number and solid lines; $\mathrm{mb} \mathrm{h}^{-1}$ ), valid 1200 GMT 26 June 1982.

tions of relatively weak QG descent in contrast to the LFM's ascent. Also, it is puzzling to note in the LFM omegas and the QG diagnosis the disparate results over western South Dakota. The diagnosed upward motion there is associated with the short-wave trough advancing across Wyoming (Fig. 2). Apparently, it is due mostly to the pattern of predicted geostrophic warm air advection (not shown). It is disturbing that any synoptic-scale numerical model could fail to produce so significant a vertical motion center in the apparent absence of strong nongeostrophic effects. The $500 \mathrm{mb}$ winds over South Dakota were approximately geostrophic (10.3 versus $8.2 \mathrm{~m} \mathrm{~s}^{-1}$; Fig. 2) and had not changed much from the previous $12 \mathrm{~h}$ (see Fig. 2 in B85).

Recognizing that it is possible for any numerical model to suffer a singularly poor run owing to any of a variety of problems, we applied the same diagnostic routine to the LFM's height data for the $12 \mathrm{~h}$ forecast beginning at 0000 GMT 26 June 1982, the time at which the convective systems in Colorado and New Mexico were becoming well organized (Fig. 1) and nongeostrophic effects were more likely to dominate the vertical motion prediction. The LFM's forecast vertical motions (Fig. 9) suggest that the ColoradoKansas border will become the center of activity, although it should be remembered that the LFM does not forecast convective storms per se. One should also note the downward motions forecast in South Dakota and the Texas panhandle. Satellite data (Fig. 10) indicate that the Colorado MCC matured and then weakened as it moved into western Kansas, and, during the same period, the New Mexico MCC grew to maturity in the Texas panhandle by 0830 GMT. Forecasters might have considered this LFM forecast (Fig. 9) to be a relatively good one, especially in light of its problems during the previous $12 \mathrm{~h}$, as discussed earlier. Had forecasters been able to access QG diagnostics based on the LFM's predicted height fields, they would have seen once again that LFM results actually contained better information than is represented in the model's $700 \mathrm{mb}$ vertical motion prediction, although this conclusion obviously results from hindsight in this case. The QG diagnostic (Fig. 11) suggests less geostrophic forcing in support of the Kansas MCC and greater forcing associated with the maturing Texaspanhandle MCC. The geostrophically forced upward motion predicted over Nebraska is contending with more stable and drier surface air, while the Texas storm system is exposed to a moisture source to its south and is embedded in a zone that is destabilizing thermodynamically (see B85). Clearly, there is potential value in considering QG diagnostic information in the context of the LFM's own predictions.

\section{Discussion}

Many facets were not considered in this investigation of LFM vertical motion prediction. One is the contri-
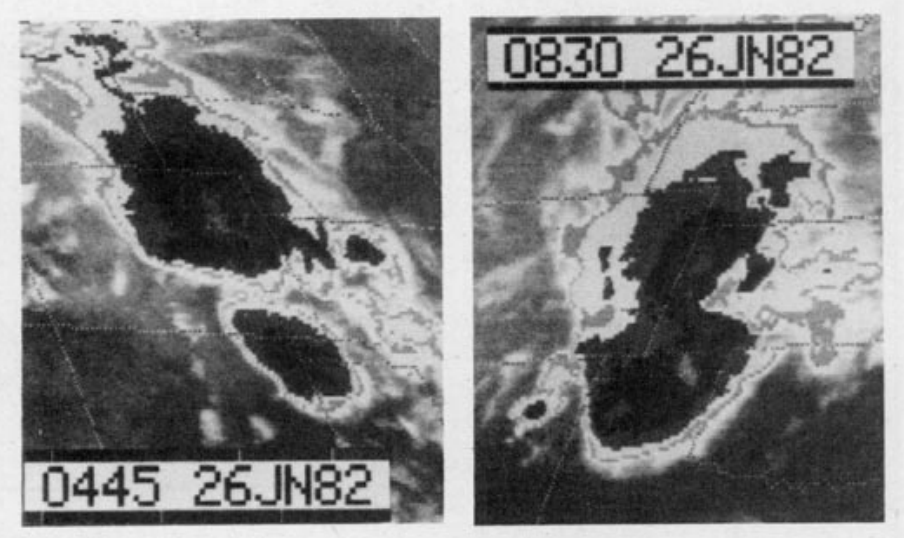

FIG. 10. Satellite IR images at times of maturing MCCs, first in Colorado (0445 GMT) and later in the Texas panhandle (0830 GMT) during the period covered by the LFM forecast shown in Fig. 9. 
bution from the boundary layer radiation parameterization (Gerrity, 1977). Simply put, where insolation is locally strong, the boundary layer will warm and contribute to upward motion in the lower troposphere. This effect might help to explain the LFM's prediction of weak upward motion in Utah, which has experienced a mostly sunny day (Fig. 1). Might diurnal heating also account for the Idaho upward motion maximum (Fig. 3)? Hardly, since Idaho experienced considerable cloudiness throughout the daytime, and the LFM itself predicted several millimeters of precipitation in that area (see B85, Figs. 1 and 5). Other facets not considered are the influence of gravitational oscillations that are not filtered from the LFM's vertical motion output, the influence of surface frictional convergence and mountain form drag. While a study of these facets might interest researchers, the results probably would be of little help to a forecaster trying to evaluate the LFM's prediction as it was presented to him/her in this case.

Judging by the location of the significant weather that developed in association with the Wyoming shortwave trough (Figs. 1 and 2; section 2), the 0000 GMT $500 \mathrm{mb}$ vertical motion (Fig. 3a) over northern Colorado was a very good prediction that could have been useful to forecasters had they been able to access it. Even the QG diagnosis of the forecast 0000 GMT 700 $\mathrm{mb}$ height fields (Figs. 3b and 8 ) was not as accurate as the $500 \mathrm{mb}$ LFM omega prediction in the placement of this upward motion center. ${ }^{\prime}$ However, the $700 \mathrm{mb}$ QG diagnostic would have alerted forecasters that the short-wave trough in Wyoming might be more active dynamically than the LFM's vertical motion prediction indicated. Also, the diagnostic would have shown that the predicted strong upward motion center over Idaho was not consistent with QG dynamics, and therefore, its strength should be suspect.

In a similar vein, the $1200 \mathrm{GMT} 700 \mathrm{mb}$ forecast (Fig. 9) cannot be considered bad guidance. In hindsight, it is just not the best guidance that was available from the LFM results. By 1200 GMT, the convective system in the Texas panhandle weakened, but persisted throughout the following day and redeveloped the next evening, suggesting continued support from geostrophic forcing. During the $12 \mathrm{~h}$ following $1200 \mathrm{GMT}$ 26 June 1982, the baroclinic wave became a closed circulation at both 850 and $700 \mathrm{mb}$, an event the LFM never did forecast.

Perhaps the question of the LFM's performance on this day is a moot one. The LFM will be replaced soon by the nested grid model. It remains to be seen whether

\footnotetext{
' Although the author cannot cite a specific reference, he has often heard the statement made by forecasters that the LFM tends to move short wavelength troughs too fast and too far north, especially in summer. With this experience, the QG diagnostics and knowing how severe storms typically develop along the Front Range of Colorado, forecasters might have made the correct adjustment to the guidance.
}

the replacement model will exhibit similar departures from QG theory on occasions such as this case represents. Still, the LFM's failure (limitation) in handling this weakly baroclinic system is real, and one does not have to go far out on a limb to surmise that similar failures can be discovered in other cases. The question remains: How can field forecasters conveniently and quantitatively assess the quality of the numerical model products?

An answer suggested by this study is the routine execution of QG diagnostic procedures that would provide a baseline, or quality check, on the LFM's performance, not only for $12 \mathrm{~h}$ forecasts, but for all forecast periods. For synoptic-scale numerical models, QG theory is the fundamental diagnostic. Furthermore, it is the simplest of balanced-model diagnostics to compute, as opposed to the geostrophic momentum model (e.g., Hoskins, 1975). This is not to say that QG diagnostics are sufficient to explain the vertical motions that produce weather in all cases. But when a numerical model that incorporates more sophisticated treatment of the physical causes of vertical motions significantly departs in its prediction from motions that are geostrophically forced, then one would hope that it does so in the direction of more accurately predicting those motions with regard to the ensuing weather. When the numerical model does depart from QG theory for reasons that are neither obvious nor physically plausible, then one should fall back upon QG diagnostics in order at least to ascertain the distribution of the fundamental adjustments that are predicted to occur.

Both this study and B85 also suggest that field forecasters might benefit from information that could be obtained simply from different combinations of existing NMC forecast products and by the development of new products. As an example of the former, if vorticity and thickness contours were combined in one panel, forecasters could more easily determine whether the model-predicted vertical motions are due mostly to geostrophic forcing through qualitative evaluation of vorticity advection by the thermal wind (Trenberth, 1978). In this regard, it would be more meaningful to present $500 \mathrm{mb}$ vorticity with, say, $700-300 \mathrm{mb}$ thickness, or better yet, $700 \mathrm{mb}$ vorticity with the $1000-500$ mb thickness. Without such a composite, forecasters may frequently diagnose upward motion based only on positive vorticity advection or only on warm temperature advection (by either the actual or geostrophic winds), neither of which is entirely appropriate. The advantage of the Hoskins et al. (1978) formulation of QG theory is that it incorporates both of these effects as well as that due to the geostrophic deformation of the existing thermal field. The obvious disadvantage is that the QG diagnostic field does not incorporate vertical motion-producing effects such as orography, diabatic heating or cooling, and horizontal advection due to the diagnosed ageostrophic circulations. However, once these effects have taken place on a large enough 


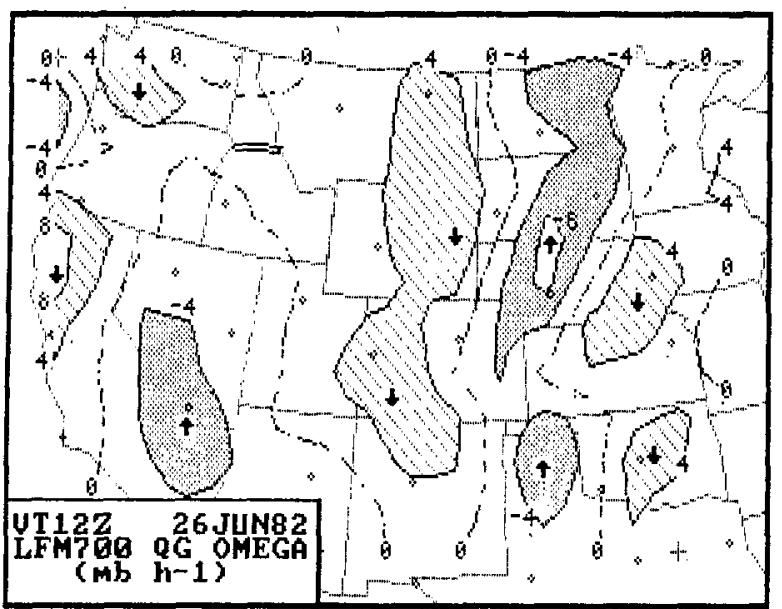

FIG. 11. Vertical motions diagnosed from $Q$-vector representation of geostrophic forcing in the $850-700 \mathrm{mb}$ layer. Isotachs are in relative units $\left(\mathrm{mb} \mathrm{h}^{-1}\right)$. Computations are based on LFM $12 \mathrm{~h}$ predicted height fields at 850 and $700 \mathrm{mb}$ for 1200 GMT 26 June 1982.

scale to be detectable in the mass field sensed by conventional rawinsonde networks, the $\mathrm{QG}$ diagnostic will reflect their contributions to mass-momentum imbalances. This is probably the explanation for the success of the QG diagnostic at 1200 GMT 26 June 1982 (Fig. 11). As explained in B85, by 0000 GMT 26 June 1982 the convective systems were already sufficiently large enough to influence the synoptic-scale mass distribution in their vicinity.

Given a significant departure of the LFM's vertical motion prediction from that determined by geostrophic forcing, how is a forecaster supposed to incorporate this information into his/her forecast? The answer to this question must be deferred until we can attain experience with this tool under more general conditions. Presently, there is no simple list of rules or guidelines one can enumerate. Recognizing the limitations of QG theory, the forecaster needs to be concerned with all the available data and draw upon his/her own knowledge base. The problem is to assess as best one can the probable influence of the physical effects unaccounted for in QG theory as they manifest themselves within the context of the larger-scale atmospheric structures and as they are influenced by the geostrophic adjustments. Qualitative information concerning these relationships can come only through experience with the QG diagnostics and the particular requirements of the forecast problem. Qualitative information will suggest quantitative studies. These facts alone recommend that forecasters, diagnosticians and modelers as well might benefit by studying their individual problems from the fundamental perspective that QG theory provides.

For modelers, one enigmatic question has been raised by this study. How is it that the LFM can predict height (mass) fields that, according to QG theory, indicate fairly accurately where significant vertical motions will occur and yet not be able to predict those same features through its own vertical motion algorithm? Perhaps having access to $Q G$ diagnostics also would assist modelers in determining which of the model's more sophisticated physical processes might be responsible for the model's departure.

Acknowledgments. Preparation of this note has benefited from discussions with my colleagues, Drs. John Brown, Charles Doswell and Robert Maddox. Mr. Barry Schwartz, TDL, kindly provided the LFM gridpoint data. Dr. Doswell, three anonymous reviewers, and Dr. Burpee in his editorial capacity are credited with numerous suggested revisions which, hopefully, have clarify the text.

\section{REFERENCES}

Barnes, S. L., 1985: Omega diagnostics as a supplement to LFM/ MOS guidance in weakly forced convective situations. Mon. Wea. Rev., 113, 2122-2141.

Gerrity, J. G., 1977: The LFM Model 1976: A documentation, 68. pp. [NTIS Rep. PB-279-419]

Hoskins, B. J., 1975: The geostrophic momentum approximation and the semi-geostrophic equations. J. Atmos. Sci., 32, 233242.

, and M. A. Pedder, 1980: The diagnosis of middle latitude synoptic development. Quart. J. Roy. Meteor. Soc., 106, 707719.

- 1. Draghici and H. C. Davies, 1978: A new look at the $\omega$ equation. Quart. J. Roy. Meteor. Soc., 104, 31-38.

Trenberth, K. E., 1978: On the interpretation of the diagnostic quasigeostrophic omega equation. Mon. Wea. Rev., 106, 131-137. 